\title{
Stereotactic radiosurgery for intradural spine tumors using cone-beam CT image guidance
}

\author{
Andrés Monserrate, MD, ${ }^{1}$ Benjamin Zussman, MD, ${ }^{1}$ Alp Ozpinar, MD, ${ }^{1}$ Ajay Niranjan, MD, MBA, ${ }^{1}$ \\ John C. Flickinger, MD, ${ }^{2,3}$ and Peter C. Gerszten, MD, MPH',
}

Departments of ${ }^{1}$ Neurological Surgery and ${ }^{2}$ Radiation Oncology, University of Pittsburgh Medical Center; and ${ }^{3}$ Pittsburgh Cancer Institute, Pittsburgh, Pennsylvania

OBJECTIVE Cone-beam CT (CBCT) image guidance technology has been widely adopted for spine radiosurgery delivery. There is relatively little experience with spine radiosurgery for intradural tumors using CBCT image guidance. This study prospectively evaluated a series of intradural spine tumors treated with radiosurgery. Patient setup accuracy for spine radiosurgery delivery using $\mathrm{CBCT}$ image guidance for intradural spine tumors was determined.

METHODS Eighty-two patients with intradural tumors were treated and prospectively evaluated. The positioning deviations of the spine radiosurgery treatments in patients were recorded. Radiosurgery was delivered using a linear accelerator with a beam modulator and CBCT image guidance combined with a robotic couch that allows positioning correction in 3 translational and 3 rotational directions. To measure patient movement, 3 quality assurance CBCTs were performed and recorded in 30 patients: before, halfway, and after the radiosurgery treatment. The positioning data and fused images of planning CT and CBCT from the treatments were analyzed to determine intrafraction patient movements. From each of 3 CBCTs, 3 translational and 3 rotational coordinates were obtained.

RESULTS The radiosurgery procedure was successfully completed for all patients. Lesion locations included cervical (22), thoracic (17), lumbar (38), and sacral (5). Tumor histologies included schwannoma (27), neurofibromas (18), meningioma (16), hemangioblastoma (8), and ependymoma (5). The mean prescription dose was 17 Gy (range 12-27 Gy) delivered in 1-3 fractions. At the halfway point of the radiation, the translational variations and standard deviations were $0.4 \pm 0.5,0.5 \pm 0.8$, and $0.4 \pm 0.5 \mathrm{~mm}$ in the lateral $(\mathrm{x})$, longitudinal $(\mathrm{y})$, and anteroposterior $(\mathrm{z})$ directions, respectively. Similarly, the variations immediately after treatment were $0.5 \pm 0.4,0.5 \pm 0.6$, and $0.6 \pm 0.5 \mathrm{~mm}$ along $x, y$, and $z$ directions, respectively. The mean rotational angles were $0.3^{\circ} \pm 0.4^{\circ}, 0.3^{\circ} \pm 0.4^{\circ}$, and $0.3^{\circ} \pm 0.4^{\circ}$ along yaw, roll, and pitch, respectively, at the halfway point and $0.5^{\circ} \pm 0.5^{\circ}, 0.4^{\circ} \pm 0.5^{\circ}$, and $0.2^{\circ} \pm 0.3^{\circ}$ immediately after treatment.

CONCLUSIONS Radiosurgery offers an alternative treatment option for intradural spine tumors in patients who may not be optimal candidates for open surgery. CBCT image guidance for patient setup for spine radiosurgery is accurate and successful in patients with intradural tumors.

https://thejns.org/doi/abs/10.3171/2016.9.FOCUS16356

KEY WORDS spine radiosurgery; intradural tumors; spine tumors; cone-beam CT

$\mathrm{S}$ TEREOTACTIC radiosurgery is an established primary or adjuvant treatment for intracranial extraaxial tumors such as schwannomas, meningiomas, and neurofibromas. Spine radiosurgery was first described by Hamilton et al. ${ }^{19}$ in 1995, and the indications for the use of spine radiosurgery are still evolving. There has been a rapid increase in the use of radiosurgery as a treatment for tumors involving the spine. ${ }^{41}$ Multiple studies have demonstrated the feasibility and clinical efficacy of spine radiosurgery for both primary and secondary malignancies. ${ }^{4-6,10,13,24,28,31,39}$

Open microsurgical resection remains the mainstay initial treatment of the majority of intradural tumors of the spine, and relatively few published series describe the treatment of intradural spine tumors with stereotactic radiosurgery. ${ }^{11,12}$ Yet for many patients, stereotactic radiosurgery may be a particularly useful alternative primary or adjuvant treatment strategy. 
A variety of techniques for conformal radiation delivery to spinal lesions have been used. $1,4,8,10,16,19,23,24,26,28,30,31,42$ Because of a lack of fixation devices to the spine, accuracy of radiation delivery has been a concern for targeting intradural tumors with radiosurgery. A concern has been raised about the ability to accurately and safely perform spine radiosurgery in such cases because of the proximity of the spinal cord and other critical structures. ${ }^{3,9}$ Recent advances in imaging and treatment-planning technologies have resulted in a higher degree of accuracy in achieving target selectivity. Accurate geometric visualization of the target is key for treatment planning. Cone-beam CT (CBCT) image guidance technology, which allows target confirmation, has been adopted for radiosurgery setup and delivery by a variety of radiosurgery delivery systems. ${ }^{20,33}$ For the past decade, our institution has used CBCT image guidance for radiosurgery delivery to intradural spine tumors. The present study was performed to prospectively evaluate the accuracy of CBCT image guidance for treatment setup for patients with intradural tumors and to describe our clinical experience with this new technology.

\section{Methods}

Between 2007 and 2016, 82 patients with intradural spine tumors underwent radiosurgery treatment at our institution. All cases had well-circumscribed tumors visible on imaging, no spinal instability, and minimal compromise of spinal cord function. Position deviations during single-fraction treatments for the first 30 patients were prospectively, quantitatively evaluated and recorded for quality assurance (QA) purposes. The study cohort included 42 men and 40 women. Patient demographics are summarized in Table 1.

Radiosurgery was delivered using either an Elekta Synergy S 6 MV linear accelerator with a beam modulator (Elekta AB) or a Varian Truebeam (Varian Medical Systems). In a plane orthogonal to the linear accelerator, the CBCT image guidance system is mounted on the gantry. The accelerators are equipped with a couch that allows for patient positioning correction in 3 translational and 3 rotational directions. Patients are immobilized with the BodyFix (total body bag, Medical Intelligence) when treatment sites are below T-6. Otherwise, a head and shoulder mask with S-board (CIVCO Medical Solutions) is used. CT images (1.5-mm slice thickness) were used to plan all spine radiosurgery treatments.

Initial patient setup was performed based on external setup marks followed by CBCT, and subsequent position adjustment was based on $\mathrm{CBCT}$ and treatment-planning CT image registration results (Fig. 1). To verify the initial patient setup and ensure the accuracy of patient positioning during treatment, 3 QA CBCT studies were performed during the procedure. The first QA study was performed immediately before the treatment started; the second, in the middle of the procedure; and the last, immediately after completing treatment. This strategy was used to monitor patient movement after the initial setup had taken place. The positioning data and fused images of the planning CT scans and the CBCT images from the treatments were analyzed to determine intrafractional patient move-
TABLE 1. Summary of patient cohort

\begin{tabular}{|c|c|}
\hline Variable & Value \\
\hline \multicolumn{2}{|l|}{ Sex } \\
\hline Female & $40(49)$ \\
\hline Male & $42(51)$ \\
\hline \multicolumn{2}{|l|}{ Age (yrs) } \\
\hline Mean & 56 \\
\hline Range & $21-93$ \\
\hline \multicolumn{2}{|l|}{ Tumor pathology } \\
\hline Schwannoma & $27(33)$ \\
\hline Meningioma & $16(20)$ \\
\hline Ependymoma & $5(6)$ \\
\hline Hemangioblastoma & $2(2)$ \\
\hline Melanocytoma & $2(2)$ \\
\hline Other & $6(7)$ \\
\hline \multicolumn{2}{|l|}{ Phakomatoses } \\
\hline Neurofibromatosis & $18(22)$ \\
\hline VHL (hemangioblastoma) & $6(7)$ \\
\hline \multicolumn{2}{|l|}{ Spinal level } \\
\hline Cervical & $22(27)$ \\
\hline Thoracic & $17(21)$ \\
\hline Lumbar & $38(46)$ \\
\hline Sacral & $5(6)$ \\
\hline \multicolumn{2}{|l|}{ Tumor vol $\left(\mathrm{mm}^{3}\right)$} \\
\hline Mean & 7.9 \\
\hline Range & $0.1-87$ \\
\hline \multicolumn{2}{|c|}{ Prescribed tumor dose (Gy) to the edge of the tumor } \\
\hline Mean & 17 \\
\hline Range & $12-27$ \\
\hline \multicolumn{2}{|l|}{ Max dose to the spinal cord (Gy) } \\
\hline Mean & 11 \\
\hline Range & $5-20$ \\
\hline \multicolumn{2}{|c|}{ Spinal cord or cauda equina vol receiving $>8 \mathrm{~Gy}\left(\mathrm{~mm}^{3}\right)$} \\
\hline Mean & 0.9 \\
\hline Range & $0-5.1$ \\
\hline $\mathrm{Hx}$ of prior fractionated radiotherapy to tumor & $14(17)$ \\
\hline
\end{tabular}

ments. From each of the 3 QA CBCTs, 3 translational and 3 rotational coordinates were obtained. Even very small patient positioning deviations observed after the initial $\mathrm{CBCT}$ were corrected in all cases.

\section{Results}

The radiosurgery procedure was successfully completed for all patients. Lesion locations were the cervical (22 patients), thoracic (17 patients), lumbar (38 patients), and sacral (5 patients) spine. Tumor sizes ranged from 0.1 to $87 \mathrm{~mm}^{3}$ for a large intradural nerve sheath tumor with extension through the neural foramen. Tumor histologies included schwannoma (27), neurofibromas (18), menin- 


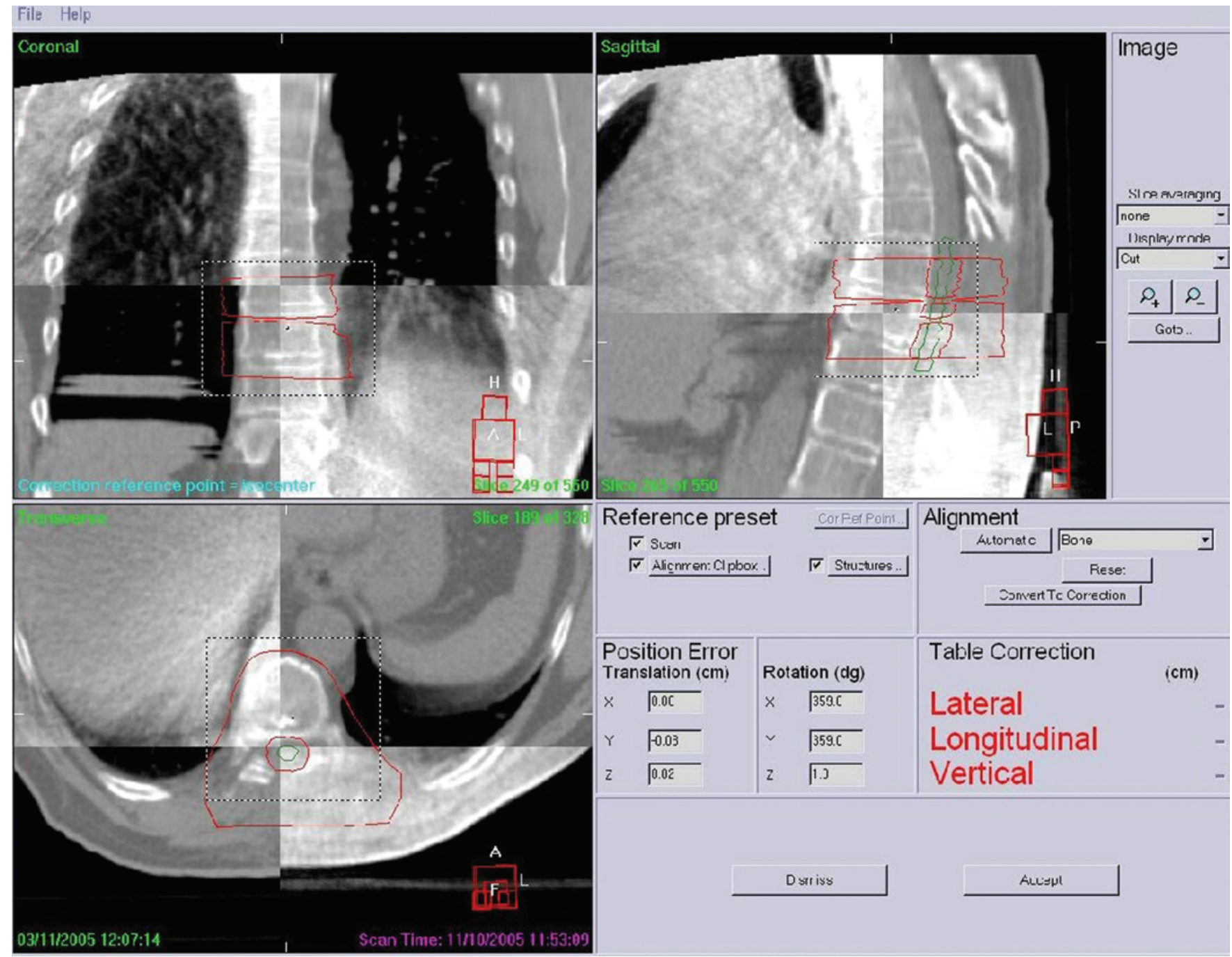

FIG. 1. Case example of the radiosurgery delivery software application. Intraoperative CBCT images and preoperative planning images are compared to calculate positional errors. Proper setup accuracy is maintained by correcting the couch position in 3 translational and 3 rotational directions.

gioma (16), and hemangioblastoma (8) (Table 2). Eighteen patients carried a diagnosis of neurofibromatosis and 6 a diagnosis of von Hippel-Lindau syndrome. Six histologies grouped as "other" included metastases (4), sarcoma (1), and unspecified nerve sheath tumor (1). Fourteen patients received prior conventional fractionated external-beam radiotherapy to the index lesion prior to radiosurgery. The treatments were delivered in a single fraction in 73 cases and in 3 fractions in 9 cases.

Table 2 provides a summary of the quantitative and qualitative variables for each tumor subtype. The prescription dose was delivered to the margin of the tumor as seen on MR fusion imaging in all cases. The majority of the meningiomas were located in the cervical spine (56\%) with a mean tumor volume of $1.98 \mathrm{~mm}^{3}$. These tumors were prescribed a mean dose of $18 \mathrm{~Gy}$. The majority of the schwannoma cases were in the lumbar spine (44\%) and had the highest mean tumor volume $\left(12.3 \mathrm{~mm}^{3}\right)$; these tumors were prescribed a mean dose of $16 \mathrm{~Gy}$. The 5 ependymoma cases were treated with a dose of $22 \mathrm{~Gy}$. All of these tumors were extramedullary myxopapillary ependymomas of the filum terminale. Tumors associated with familial phakomatoses were divided into neurofibromatosis (both Type 1 and Type 2) $(\mathrm{n}=18)$ and von Hippel-Lindau $(n=6)$. Tumors in patients with neurofibromatosis were mostly in the lumbar spine (61\%), had a mean volume of 11. $2 \mathrm{~mm}^{3}$, and were treated with a mean dose of $18 \mathrm{~Gy}$. In comparison, von Hippel-Lindau-related hemangioblastoma tumors had a mean volume of $2.2 \mathrm{~mm}^{3}$ and were treated with a mean dose of $19 \mathrm{~Gy}$.

Doses to the spinal cord and cauda equina were carefully monitored during the treatment-planning process and were kept as low as reasonably possible. A comparison between the location of the tumors within the spine and the volumes and doses is presented in Table 3. The prescribed dose to the tumors of the cervical spine region was 13-27 Gy delivered in 1-3 fractions (mean 19 Gy). A mean volume of the spinal cord of less than $0.9 \mathrm{~mm}^{3}$ received a dose greater than $8 \mathrm{~Gy}$. The tumors of the thoracic spine had the smallest tumor volume $\left(2.9 \mathrm{~mm}^{3}\right)$ with 
TABLE 2. Summary of data by tumor histology

\begin{tabular}{|c|c|c|c|c|c|c|}
\hline Tumor Histology & $\begin{array}{l}\text { No. of } \\
\text { Tumors }\end{array}$ & $\begin{array}{l}\text { Female } \\
\text { Sex (\%) }\end{array}$ & $\begin{array}{c}\text { Mean Age } \\
\text { (range) in Yrs }\end{array}$ & No. of Spinal Levels & $\begin{array}{l}\text { Mean Tumor Vol } \\
\text { (range) in } \mathrm{mm}^{3}\end{array}$ & $\begin{array}{c}\text { Mean Max } \\
\text { Tumor Dose (Gy) }\end{array}$ \\
\hline Schwannoma & 27 & $13(48)$ & $62(29-90)$ & 9 cervical; 5 thoracic; 12 lumbar; 1 sacral & $12.3(0.5-87)$ & $16(13-23)$ \\
\hline Meningioma & 16 & $15(94)$ & $61(39-93)$ & 9 cervical; 6 thoracic; 1 lumbar; 0 sacral & $2.0(0.4-7.8)$ & $18(12-26)$ \\
\hline Ependymoma & 5 & $2(40)$ & $60(30-79)$ & 0 cervical; 1 thoracic; 3 lumbar; 1 sacral & $5.0(0.2-10.7)$ & $22(14-27)$ \\
\hline Primary hemangioblastoma & 2 & $0(0)$ & $28(21-35)$ & 0 cervical; 0 thoracic; 2 lumbar; 0 sacral & $8.9(0.9-17.0)$ & $15(14-15)$ \\
\hline Melanocytoma & 2 & $0(0)$ & $43(43)$ & 0 cervical; 1 thoracic; 1 lumbar; 0 sacral & $2.8(1.0-4.7)$ & $16(13-18)$ \\
\hline Other & 6 & $2(33)$ & $52(43-55)$ & 0 cervical; 0 thoracic; 5 lumbar; 1 sacral & $4.5(0.4-20.0)$ & $15(14-17)$ \\
\hline \multicolumn{7}{|l|}{ Phakomatoses } \\
\hline Neurofibromatosis & 18 & $6(33)$ & $49(25-69)$ & 4 cervical; 2 thoracic; 11 lumbar; 1 sacral & $11.2(0.7-66.8)$ & $18(13-27)$ \\
\hline VHL (hemangioblastoma) & 6 & $2(33)$ & $55(32-80)$ & 0 cervical; 2 thoracic; 3 lumbar; 1 sacral & $2.2(0.3-2.2)$ & $19(14-26)$ \\
\hline
\end{tabular}

a mean $0.4 \mathrm{~mm}^{3}$ of the spinal cord receiving greater than 8 Gy. The majority of tumors were located in the lumbar region, with a mean volume of $7.4 \mathrm{~mm}^{3}$. The maximum dose to the lumbar cauda equina ranged from 5 to 21 Gy (mean 12 Gy). Five tumors were located in the sacral spine, with a mean volume of $5.5 \mathrm{~mm}^{3}$. Tumors of the sacral region received relatively higher doses given the lack of concern for the spinal cord itself; a mean $1.2 \mathrm{~mm}^{3}$ of the cauda equina of the sacrum received greater than $8 \mathrm{~Gy}$. The maximum dose to neural structures in the sacral area ranged from 11 to 21 Gy (mean 13 Gy).

The initial 30 cases were analyzed for the accuracy of treatment setup. Intraoperative CBCT imaging and preoperative imaging for treatment planning are depicted in Fig. 1. At the completion of the middle of the radiation delivery, the mean translational deviations and 1 standard deviation were $0.4 \pm 0.5,0.5 \pm 0.8$, and $0.4 \pm 0.5 \mathrm{~mm}$ in the lateral (x), longitudinal (y) and anteroposterior (z) directions, respectively (Table 4 ). The mean rotational deviations with 1 standard deviation were $0.3^{\circ} \pm 0.4^{\circ}, 0.3^{\circ}$ $\pm 0.4^{\circ}$, and $0.3^{\circ} \pm 0.4^{\circ}$ in the pitch $(\mathrm{x})$, roll $(\mathrm{y})$, and yaw (z) directions, respectively. Similarly, the deviations after completion of radiation delivery were $0.5 \pm 0.4,0.5 \pm 0.6$, and $0.6 \pm 0.5 \mathrm{~mm}$ along $\mathrm{x}, \mathrm{y}$, and $\mathrm{z}$ directions, respectively; the rotational deviations were $0.5^{\circ} \pm 0.5^{\circ}, 0.4^{\circ} \pm 0.5^{\circ}$, and $0.2^{\circ} \pm 0.3^{\circ}$ in the pitch $(\mathrm{x})$, roll $(\mathrm{y})$, and yaw $(\mathrm{z})$ directions, respectively. Positioning deviations did not differ when compared by treatment segment of the vertebral column (i.e., cervical, thoracic, or lumbar). However, in general, more difficulties in patient setup were observed in the cases of cervical spine targets compared with thoracic and lumbar ones. Multiple CBCT images and patient repositioning before the treatment were often required to set up cervical spine patients accurately. Figure 2 demonstrates a case example of a symptomatic L-3 schwannoma treated with 12 coplanar beams in a single fraction.

\section{Discussion}

Stereotactic body radiosurgery has emerged as a minimally invasive treatment option in the multidisciplinary management of tumors located within or adjacent to the vertebral bodies or spinal cord. ${ }^{4-6,10,24,28,31,37,41}$ The goals of radiosurgery for spinal tumors include local tumor control, improvement in existing rates of clinical response, and reduction of the treatment rate by increasing the biological equivalent dose. ${ }^{32}$

While there is ample literature focused on the use of radiosurgery for the management of malignant spinal neoplasms $^{4-7,10,11,16,21,23,24,26-28,30,41,42}$ and there are several studies that present radiosurgery as an alternative for the management of benign spinal tumors, ${ }^{4,10,11,12,15,17,25}$ this study represents one of the largest cohorts to date describing the use of radiosurgery using CBCT image guidance for intradural spinal tumors. Shin et al. reported the clinical results of radiosurgery for intradural metastatic lesions. In their series, 9 patients with intradural tumors underwent radiosurgery for 11 lesions. ${ }^{36}$ These investigators found radiosurgery to be both safe and effective. A concern has been raised regarding the risk of malignant transformation from irradiated peripheral nerve tumors in patients with neurofibromatosis. No case of malignant transformation has been published to date after radiosurgery. There is a possibility that high-dose, highly conformal radiosurgery would lower the risk of radiation-induced malignant transformation compared with the conventional lower dose, fractionated radiotherapy due to a different radiobiological mechanism of action.

TABLE 3. Summary of tumor volume and doses by spinal level

\begin{tabular}{ccccc}
\hline $\begin{array}{c}\text { No. of Spinal } \\
\text { Levels }\end{array}$ & $\begin{array}{c}\text { Mean Tumor Vol } \\
\text { (range) in } \mathrm{mm}^{3}\end{array}$ & $\begin{array}{c}\text { Mean Max Tumor } \\
\text { Dose (range) in Gy }\end{array}$ & $\begin{array}{c}\text { Mean Max Spinal Cord/Cauda } \\
\text { Equina Dose (range) in Gy }\end{array}$ & $\begin{array}{c}\text { Mean Spinal Cord/Cauda Equina Vol } \\
\text { Receiving }>8 \text { Gy (range) in } \text { mm }^{3}\end{array}$ \\
\hline 22 cervical & $13.4(0.4-87.5)$ & $19(13-27)$ & $12(7-21)$ & $0.9(0-5.1)$ \\
\hline 17 thoracic & $2.9(0.3-13.6)$ & $15(12-20)$ & $11(8-15)$ & $0.4(0-1.2)$ \\
\hline 38 lumbar & $7.4(0.1-57.1)$ & $17(13-20)$ & $12(5-21)$ & $1(0-4.6)$ \\
\hline 5 sacral & $5.5(0.7-7.9)$ & $18(15-27)$ & $13(11-21)$ & $1.2(0-3.3)$ \\
\hline
\end{tabular}


TABLE 4. Summary of translational and rotational deviations measured on CBCT images obtained in the middle and at the end of the spine radiosurgery treatment in 30 patients with intradural tumors

\begin{tabular}{lccccccc}
\hline & \multicolumn{3}{c}{ Translational Deviations $(\mathrm{mm})$} & & \multicolumn{3}{c}{ Rotational Deviations $\left(^{\circ}\right)$} \\
\cline { 2 - 3 } \cline { 6 - 8 } Variable & $\mathrm{X}$ (lateral) & $\mathrm{Y}$ (longitudinal) & $\mathrm{Z}(\mathrm{AP})$ & & $\mathrm{X}$ (pitch) & $\mathrm{Y}($ roll) & $\mathrm{Z}(\mathrm{yaw})$ \\
\hline Middle & $0.4 \pm 0.5$ & $0.5 \pm 0.8$ & $0.4 \pm 0.5$ & & $0.3 \pm 0.4$ & $0.3 \pm 0.4$ & $0.3 \pm 0.4$ \\
\hline End & $0.5 \pm 0.4$ & $0.5 \pm 0.6$ & $0.6 \pm 0.5$ & & $0.5 \pm 0.5$ & $0.4 \pm 0.5$ & $0.2 \pm 0.3$ \\
\hline
\end{tabular}

AP = anteroposterior

To deliver conformal doses necessary for extracranial radiosurgery, the current radiosurgery techniques use either image-guided robotic technology to adjust the trajectory of the beam delivery system or micromultileaf collimated beams to generate intensity-modulated radiotherapy (IMRT). ${ }^{8,38,40}$ The treatment plan must be confor-
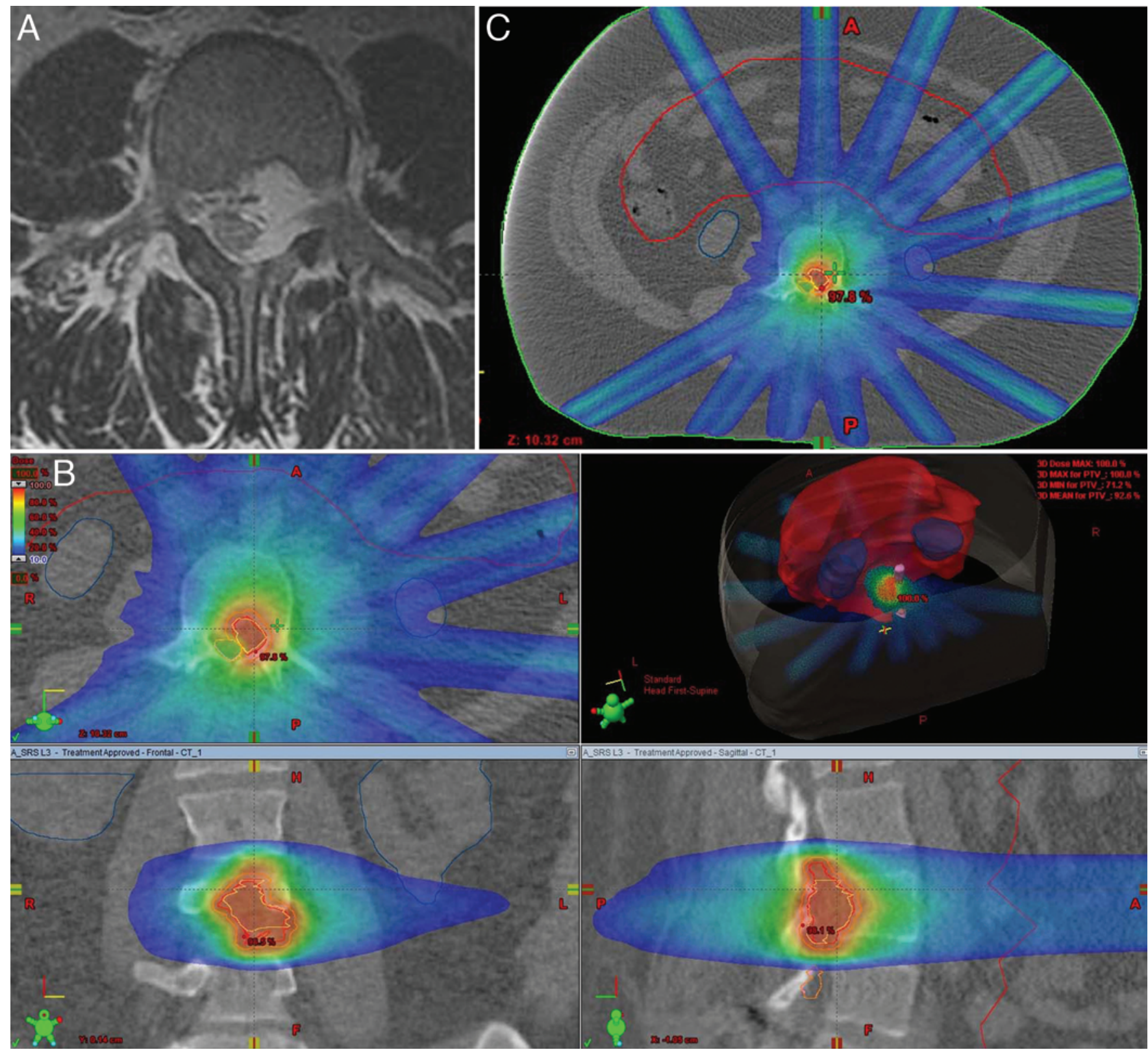

FIG. 2. Axial gadolinium-enhanced MR image obtained in a 32-year-old man with a biopsy-proven left L-3 schwannoma associated with significant radicular pain (A). Radiosurgery was offered to avoid the morbidity of resection of this tumor. Images of the treatment plan (B). The prescribed dose to the gross tumor volume was 16 Gy delivered using 12 coplanar IMRT beams (C) in a single fraction. The gross tumor volume was $7.3 \mathrm{~cm}^{3}$. The patient reported complete pain resolution at 1-month follow-up. 
mal to the tumor, while achieving steep dose gradients at the margin and the immediate surrounding normal tissue. With the more widespread adoption of spine radiosurgery as part of the multimodality postoperative treatment paradigm of spinal neoplasms, a significant number of patients referred for spine radiosurgery have intradural tumors. The present study was undertaken to evaluate the efficacy of CBCT and safety of CBCT-guided spine radiosurgery for patients with intradural tumors.

Online image guidance represents a significant advance in the field of spine radiosurgery. The safety and efficacy of this technique (image-guided IMRT) in the management of spinal and paraspinal tumors has been investigated. ${ }^{22,40}$ Online image guidance provides a high degree of precision in tumor targeting, which is required for the safe and effective treatment of intradural spinal tumors.

A variety of conventional linear accelerator-based systems are now available for spine radiosurgery. For delivery of radiosurgery in this series of patients, a rotatable gantry allows $360^{\circ}$ rotation of the source for multiple beam directions. Highly conformal radiosurgery plans can be created by selecting the number of beams, beam angles or directions, and modulation of beam intensity by the IMRT stepand-shoot technique. Critical structures can be avoided by selecting proper beam angles. The beam can be further modified using a multileaf collimator, which can shape the field size and modulate the beam intensity. The small size of these leaves (millimeters) allows for the accurate delivery of radiation to extremely small field sizes. Each beam of radiation can be considered to be combination of several beamlets (segments) each of which can be modulated into varying intensities using a multileaf collimator (IMRT) ${ }^{41}$

Cone-beam CT imaging for radiosurgery is a relatively recent imaging technique that uses a gantry-mounted kilovoltage source and detector. ${ }^{34}$ Several hundred projection images can be acquired by 1 gantry rotation. Other systems use megavoltage cone-beam imaging..$^{20}$ These are converted into CT-like axial slices. The cone-beam scans provide extremely high spatial resolution of both bony and soft-tissue structures, which helps in achieving submillimeter targeting accuracy. ${ }^{41}$ The linear accelerator platforms used to treat the patients in this series are optimized for image-guided radiation therapy by enabling the acquisition of a high-definition 3D volume image at the time of treatment with the patient in the treatment position. The machine combines a linear accelerator with a fully integrated onboard 3D volume imaging system that allows for the target to be visualized at the precise time of treatment while the patient is on the treatment couch. The couch can be adjusted to ensure that the radiation beam is directed precisely to the target.

The current study demonstrated our technique and experience using CBCT technology for radiosurgery image guidance for intradural tumors of the spine. These position variations do not differ significantly from our QA experience in other spine radiosurgery cases. ${ }^{14}$ It was demonstrated in this study that careful verification of patient setup before and during the treatment can ensure high setup accuracy typically within $0.5 \mathrm{~mm}$ in 3 translational coordinates and $0.5^{\circ}$ in 3 rotational angles.

The low radiation tolerance of the spinal cord is the pri- mary limiting factor in the dose of therapeutic ionizing radiation that can be used for spinal tumors. Although a consensus has not been reached regarding the exact dose of radiation tolerated by the spinal cord, $2,18,29,35,38$ our pretreatment planning aims to deliver a dose less than 8 Gy to both the spinal cord and cauda equina.

\section{Conclusions}

Radiosurgery offers an alternative treatment option for intradural spine tumors in patients who may not be optimal candidates for open surgery. Cone-beam CT image guidance for patient setup for spine radiosurgery is accurate and safe in patients with intradural tumors.

\section{References}

1. Adler JR Jr, Chang SD, Murphy MJ, Doty J, Geis P, Hancock SL: The Cyberknife: a frameless robotic system for radiosurgery. Stereotact Funct Neurosurg 69:124-128, 1997

2. Baumann M, Budach V, Appold S: [Radiation tolerance of the human spinal cord.] Strahlenther Onkol 170:131-139, 1994 (Ger)

3. Belka C, Budach W, Kortmann RD, Bamberg M: Radiation induced CNS toxicity-molecular and cellular mechanisms. Br J Cancer 85:1233-1239, 2001

4. Benzil DL, Saboori M, Mogilner AY, Rocchio R, Moorthy CR: Safety and efficacy of stereotactic radiosurgery for tumors of the spine. J Neurosurg 101 (Suppl 3):413-418, 2004

5. Bilsky MH, Yamada Y, Yenice KM, Lovelock M, Hunt M, Gutin PH, et al: Intensity-modulated stereotactic radiotherapy of paraspinal tumors: a preliminary report. Neurosurgery 54:823-831, 2004

6. Chang EL, Shiu AS, Lii MF, Rhines LD, Mendel E, Mahajan A, et al: Phase I clinical evaluation of near-simultaneous computed tomographic image-guided stereotactic body radiotherapy for spinal metastases. Int J Radiat Oncol Biol Phys 59:1288-1294, 2004

7. Chang SD, Adler JR Jr: Current status and optimal use of radiosurgery. Oncology (Williston Park) 15:209-216, 219221,2001

8. Cosgrove VP, Jahn U, Pfaender M, Bauer S, Budach V, Wurm RE: Commissioning of a micro multi-leaf collimator and planning system for stereotactic radiosurgery. Radiother Oncol 50:325-336, 1999

9. Daly ME, Choi CY, Gibbs IC, Adler JR Jr, Chang SD, Lieberson RE, et al: Tolerance of the spinal cord to stereotactic radiosurgery: insights from hemangioblastomas. Int J Radiat Oncol Biol Phys 80:213-220, 2011

10. De Salles AA, Pedroso AG, Medin P, Agazaryan N, Solberg T, Cabatan-Awang C, et al: Spinal lesions treated with Novalis shaped beam intensity-modulated radiosurgery and stereotactic radiotherapy. J Neurosurg 101 (Suppl 3):435-440, 2004

11. Dodd RL, Ryu MR, Kamnerdsupaphon P, Gibbs IC, Chang SD Jr, Adler JR Jr: CyberKnife radiosurgery for benign intradural extramedullary spinal tumors. Neurosurgery 58:674-685, 2006

12. Gerszten PC, Burton SA, Ozhasoglu C, McCue KJ, Quinn AE: Radiosurgery for benign intradural spinal tumors. Neurosurgery 62:887-896, 2008

13. Gerszten PC, Germanwala A, Burton SA, Welch WC, Ozhasoglu C, Vogel WJ: Combination kyphoplasty and spinal radiosurgery: a new treatment paradigm for pathological fractures. J Neurosurg Spine 3:296-301, 2005

14. Gerszten PC, Monaco EA III, Quader M, Novotny J Jr, Kim JO, Flickinger JC, et al: Setup accuracy of spine radiosurgery using cone beam computed tomography image guidance in 
patients with spinal implants. J Neurosurg Spine 12:413420, 2010

15. Gerszten PC, Ozhasoglu C, Burton SA, Vogel WJ, Atkins BA, Kalnicki S, et al: CyberKnife frameless single-fraction stereotactic radiosurgery for benign tumors of the spine. Neurosurg Focus 14(5):e16, 2003

16. Gerszten PC, Welch WC: Cyberknife radiosurgery for metastatic spine tumors. Neurosurg Clin N Am 15:491-501, 2004

17. Gibbs IC, Chang SD, Dodd RL, Adler JR Jr: Radiosurgery for benign extramedullary tumors of the spine, in Gerszten PC, Ryu SI (eds): Spine Radiosurgery. New York: Thieme, 2015, pp 164-169

18. Gibbs IC, Patil C, Gerszten PC, Adler JR Jr, Burton SA: Delayed radiation-induced myelopathy after spinal radiosurgery. Neurosurgery 64 (2 Suppl):A67-A72, 2009

19. Hamilton AJ, Lulu BA, Fosmire H, Stea B, Cassady JR: Preliminary clinical experience with linear accelerator-based spinal stereotactic radiosurgery. Neurosurgery 36:311-319, 1995

20. Hansen EK, Larson DA, Aubin M, Chen J, Descovich M, Gillis AM, et al: Image-guided radiotherapy using megavoltage cone-beam computed tomography for treatment of paraspinous tumors in the presence of orthopedic hardware. Int $\mathbf{J}$ Radiat Oncol Biol Phys 66:323-326, 2006

21. Hitchcock E, Kitchen G, Dalton E, Pope B: Stereotactic LINAC radiosurgery. Br J Neurosurg 3:305-312, 1989

22. Lovelock DM, Hua C, Wang P, Hunt M, Fournier-Bidoz N, Yenice K, et al: Accurate setup of paraspinal patients using a noninvasive patient immobilization cradle and portal imaging. Med Phys 32:2606-2614, 2005

23. Medin PM, Solberg TD, De Salles AA, Cagnon CH, Selch MT, Johnson JP, et al: Investigations of a minimally invasive method for treatment of spinal malignancies with LINAC stereotactic radiation therapy: accuracy and animal studies. Int J Radiat Oncol Biol Phys 52:1111-1122, 2002

24. Milker-Zabel S, Zabel A, Thilmann C, Schlegel W, Wannenmacher M, Debus J: Clinical results of retreatment of vertebral bone metastases by stereotactic conformal radiotherapy and intensity-modulated radiotherapy. Int J Radiat Oncol Biol Phys 55:162-167, 2003

25. Peker S, Cerçi A, Ozgen S, Isik N, Kalelioglu M, Pamir MN: Spinal meningiomas: evaluation of 41 patients. J Neurosurg Sci 49:7-11, 2005

26. Pirzkall A, Lohr F, Rhein B, Höss A, Schlegel W, Wannenmacher $\mathrm{M}$, et al: Conformal radiotherapy of challenging paraspinal tumors using a multiple arc segment technique. Int J Radiat Oncol Biol Phys 48:1197-1204, 2000

27. Rock JP, Ryu S, Yin FF: Novalis radiosurgery for metastatic spine tumors. Neurosurg Clin N Am 15:503-509, 2004

28. Ryu S, Fang Yin F, Rock J, Zhu J, Chu A, Kagan E, et al: Image-guided and intensity-modulated radiosurgery for patients with spinal metastasis. Cancer 97:2013-2018, 2003

29. Ryu S, Jin JY, Jin R, Rock J, Ajlouni M, Movsas B, et al: Partial volume tolerance of the spinal cord and complications of single-dose radiosurgery. Cancer 109:628-636, 2007

30. Ryu S, Rock J, Rosenblum M, Kim JH: Patterns of failure after single-dose radiosurgery for spinal metastasis. J Neurosurg 101 (Suppl 3):402-405, 2004

31. Ryu SI, Chang SD, Kim DH, Murphy MJ, Le QT, Martin DP, et al: Image-guided hypo-fractionated stereotactic radiosurgery to spinal lesions. Neurosurgery 49:838-846, 2001
32. Sahgal A, Ames C, Chou D, Ma L, Huang K, Xu W, et al: Stereotactic body radiotherapy is effective salvage therapy for patients with prior radiation of spinal metastases. Int $\mathbf{J}$ Radiat Oncol Biol Phys 74:723-731, 2009

33. Saw CB, Ayyangar KM, Zhen W, Thompson RB, Enke CA: Commissioning and quality assurance for MLC-based IMRT. Med Dosim 26:125-133, 2001

34. Saw CB, Yang Y, Li F, Yue NJ, Ding C, Komanduri K, et al: Performance characteristics and quality assurance aspects of kilovoltage cone-beam CT on medical linear accelerator. Med Dosim 32:80-85, 2007

35. Schultheiss TE: The radiation dose-response of the human spinal cord. Int J Radiat Oncol Biol Phys 71:1455-1459, 2008

36. Shin DA, Huh R, Chung SS, Rock J, Ryu S: Stereotactic spine radiosurgery for intradural and intramedullary metastasis. Neurosurg Focus 27(6):E10, 2009

37. Shiu AS, Chang EL, Ye JS, Lii M, Rhines LD, Mendel E, et al: Near simultaneous computed tomography image-guided stereotactic spinal radiotherapy: an emerging paradigm for achieving true stereotaxy. Int J Radiat Oncol Biol Phys 57:605-613, 2003

38. Shiu AS, Kooy HM, Ewton JR, Tung SS, Wong J, Antes K, et al: Comparison of miniature multileaf collimation (MMLC) with circular collimation for stereotactic treatment. Int J Radiat Oncol Biol Phys 37:679-688, 1997

39. Song DY, Kavanagh BD, Benedict SH, Schefter T: Stereotactic body radiation therapy. Rationale, techniques, applications, and optimization. Oncology (Williston Park) 18:1419-1430, 1432, 1435-1436, 2004

40. Yamada Y, Bilsky MH, Lovelock DM, Venkatraman ES, Toner S, Johnson J, et al: High-dose, single-fraction imageguided intensity-modulated radiotherapy for metastatic spinal lesions. Int J Radiat Oncol Biol Phys 71:484-490, 2008

41. Yamada Y, Lovelock DM, Bilsky MH: A review of imageguided intensity-modulated radiotherapy for spinal tumors. Neurosurgery 61:226-235, 2007

42. Yin FF, Ryu S, Ajlouni M, Yan H, Jin JY, Lee SW, et al: Image-guided procedures for intensity-modulated spinal radiosurgery. Technical note. J Neurosurg 101 (Suppl 3):419424,2004

\section{Disclosures}

The authors report no conflict of interest concerning the materials or methods used in this study or the findings specified in this paper.

\section{Author Contributions}

Conception and design: Gerszten, Niranjan, Flickinger. Acquisition of data: Gerszten, Niranjan, Flickinger. Analysis and interpretation of data: Gerszten, Monserrate, Ozpinar. Drafting the article: all authors. Critically revising the article: Gerszten, Monserrate. Reviewed submitted version of manuscript: all authors. Approved the final version of the manuscript on behalf of all authors: Gerszten. Administrative/technical/material support: Gerszten. Study supervision: Gerszten.

\section{Correspondence}

Peter C. Gerszten, Department of Neurological Surgery, Presbyterian University Hospital, Ste. B-400, 200 Lothrop St., Pittsburgh, PA 15213.email: gersztenpc@upmc.edu. 